\title{
Proposal of a system for diagnosing with inefficient occupant behaviour and systems malfunctioning in the household sector
}

\author{
G. Comodi ${ }^{1}$, A. Giantomassi ${ }^{2}$, A. Arteconi ${ }^{3}$, \\ C. Meloni ${ }^{4} \&$ S. Pizzuti ${ }^{4}$ \\ ${ }^{I}$ DIISM, Dipartimento di Ingegneria Industriale e Scienze Matematiche, \\ Università Politecnica delle Marche, Ancona, Italy \\ ${ }^{2}$ DII, Dipartimento di Ingegneria dell'Informazione, \\ Università Politecnica delle Marche, Ancona, Italy \\ ${ }^{3}$ Università Telematica E-Campus, Novedrate (CO), Italy \\ ${ }^{4}$ ENEA, Unità Tecnica Tecnologie avanzate per l'Energia e l'Industria \\ (UTTEI), Roma, Italy
}

\begin{abstract}
One of the key factors in curbing energy consumption in the household sector, together with energy efficiency and renewable energies, is widely recognized to be the amendment of occupant erroneous behaviour and systems malfunctioning, mainly explained by the lack of awareness of the final user. The aim of this work is to propose a diagnostic system in the household sector which can improve the users' awareness with respect to the energy consumption in final uses. In particular, this paper presents an energy, environmental and economic analysis of different diagnostics systems, corresponding to different degrees of complexity and cost. Given a reference occupancy and thermal user profile, for each diagnostic system the relevant energy consumption is assessed by simulation and the subsequent economic savings are calculated and compared to the diagnostic system cost in order to evaluate the payback period of the architecture proposed. Keywords: domotics, energy conservation, urban pollution.
\end{abstract}




\section{Introduction}

The household sector in Italy has a wide and undeveloped potential for emission reductions if compared with the tertiary or industrial sector. The main reason is fundamentally economic. In fact, while with respect to the large users of both the tertiary and the industrial sectors, energy efficiency initiatives often translate in a remarkable reduction of the energy bill and consequently in a short payback period, investments in energy efficiency in the domestic sector are sometimes paid back in a period considered too long by the energy final users. The result is that energy efficient technologies have been penetrating tertiary and industrial sector in the last years, while the technology stock of the household sector is backward compared to the best available technologies in commerce. Actually, this trend has been changing since 2005 when the Italian Government enforced a tax reduction and an incentive mechanism (known as "white certificates") aimed at boosting energy efficiency investments in all sectors [1]. Nevertheless, with regards to households, these actions had effect only with respect to technologies with a short PBP, as the replacement of the old and outdated (mainly electrical) appliances with newer and more efficient ones (e.g. fridges, lamps, dishwashers, boilers...).Other more energy effective (and more expensive) interventions, such as those concerning the energy efficiency of buildings, although present and compulsory for new buildings, have not reached a market penetration on the existing housing stock able to be appreciated in terms of energy reduction, due to their high initial cost and their long payback period. It is important to stress this point for, at least, two reasons. First, most of the primary energy consumption $(80 \%)$ in the Italian household sector is ascribable to thermal energy use, mainly ambient heating, and just a $20 \%$ is due to electricity [2]. Second, since the Italian electrical power generation sector is characterized by centralized production in large power plants far from most of the cities, the second major cause of the local urban pollution after traffic emission is represented by heating systems [3]. Finally, it is worth noting that energy efficiency is only one side of the coin of household consumption; the other side is the "occupant behaviour". In fact, the benefits achievable with energy efficiency could be either amplified or neutralized by, respectively good or bad practices carried out by the final users [4]. In particular, it is important to point out that often the final user bad practices are driven by lack of unawareness or ignorance rather than bad faith, so that training the final user with respect to energy awareness can be more effective and cheaper than other policies [5]. The aim of this work is to evaluate the potential of reduction of heating energy consumption achievable by means of a system able to (i) diagnose inefficient occupant behaviour and systems malfunctioning in the household sector and (ii) suggest good practices of energy conservation. Since the main challenge is the retrofit of existing buildings, the components of a system proposed are the least intrusive and cheapest available. This paper is organized as follows: after the Introduction, section 2 presents the connections between urban air quality and civil heating systems; section 3 deals with occupant behaviour; section 4 presents the Interactive Building Network; section 5 reports the methodology to carry out the simulation of "occupant 
behaviours"; section 6 shows the results of the multi-scale component analysis diagnosis technique; energy, economic and environmental results are presented and discussed in section 7 which also reports some considerations on the "marginal energy and economic" benefits for the occupant and on the cost of the domotic platform proposed.

\section{Air quality versus heating systems in the urban environment}

Italian legislation, with the law n. 10 of 1991 and following decrees, forces Italian municipalities to verify the condition and the maintenance of heating systems existing in its territory. In fact, heating systems are the cause of a relevant part of urban pollution. In particular, according to ISPRA a major Italian institution for environmental research and protection, civil heating systems are responsible for $9 \%$ of volatile organic compounds (VOC), 19\% of PM10 and $27 \%$ of PM2.5 [3]. As an example, the Italian municipality of Pesaro published the results of a survey on heating systems in the town [6]: the boilers whose thermal power size is lower than $35 \mathrm{kWt}$ are 32,733 mainly fed by natural gas, with a yearly consumption estimated equal to $36.3 \mathrm{Mm}^{3}$. The resulting emissions are: $62,318 \mathrm{t}$ of $\mathrm{CO}_{2}$ and $49,658 \mathrm{t}$ of $\mathrm{NO}_{\mathrm{x}}$ [7]. Generally speaking, according to the IPCC [8], the GHG emissions due to the combustion of natural gas are $56,100 \mathrm{~kg}$ of $\mathrm{CO}_{2}, 1 \mathrm{~kg}$ of $\mathrm{CH}_{4}$ and $0.1 \mathrm{~kg}$ of $\mathrm{N}_{2} \mathrm{O}$ for every TJ of net calorific value of natural gas being burnt. Instead the boilers $\mathrm{NO}_{\mathrm{X}}$ emissions are ruled by a European norm [9] that sets as limit in the combustion products $150 \mathrm{mg} / \mathrm{kWh}$ of $\mathrm{NO}_{\mathrm{X}}$ for ambient boilers (85\% of the Italian market) and $70 \mathrm{mg} / \mathrm{kWh}$ of $\mathrm{NO}_{\mathrm{X}}$ for condensing boilers (15\% of the Italian market). The abovementioned figures give an idea of the environmental impact of heating systems on the air quality in cities, making clear the importance of reducing fuel consumption for heating purposes in a sustainable scenario.

\section{3 “Occupant behaviour": best and bad practices}

Energy consumption in household sector can be curbed with a combination of both energy efficiency and energy conservation. The former is strictly connected with the performances of a product or device (e.g. boilers, lamps, electrical and thermal appliances, building) whilst the latter is linked to the final user's behaviour. Regarding the energy conservation, the best practices commonly suggested by literature are connected with heating systems and their control devices [10]: i) installation of a thermostat in the apartment; ii) installation of a temperature control (e.g. radiator thermostat) in each room of the apartment; iii) control of openings of external windows and doors; and iv) lowering of the heating water temperature outlet of the boiler. Suggested settings for thermostat are: i) comfort ambient temperature of $18-20^{\circ} \mathrm{C}$ when occupant is in the house during the day; ii) lower the comfort temperature at $16^{\circ} \mathrm{C}$ during the night; and iii) further lower the temperature at $13-15^{\circ} \mathrm{C}$ when nobody is inside the house for more than $24 \mathrm{~h}$. 


\section{Design of the interactive building network architecture for the household sector}

The Interactive Building Network (IBN) is a sensor network able both to suggest good practices and set points and to identify anomalous events such as temperature profiles different from the best practices or from the ones set by the user; performance degradation (decay) of sensors or actuators. The main events chosen to be detected are reported in Table 1.

Table 2 shows a preliminary list of sensors and actuator to be implemented in the IBN.

Table 1: $\quad$ Event to diagnose.

\begin{tabular}{|c|c|c|}
\hline$\#$ & Event to diagnose & When \\
\hline 1 & Openings of external doors and windows & Always \\
\hline 2 & Malfunctioning of thermostat & Only if thermostat is mounted \\
\hline 3 & Malfunctioning of radiator thermostat & Only for temperature control in each room \\
\hline
\end{tabular}

Table 2: $\quad$ IBN Sensors/actuators.

\begin{tabular}{|c|c|c|}
\hline$\#$ & Sensors/actuators & Data/information transmission modes \\
\hline 1 & Temperature & - Wire; \\
\hline 2 & $\begin{array}{c}\text { Contact sensors for external } \\
\text { windows and doors }\end{array}$ & $\begin{array}{l}\text { - Home Radio Frequency (HomeRF); } \\
\text { - Wi-fi; }\end{array}$ \\
\hline 3 & Thermostat & - $\quad$ Zig-bee; \\
\hline 4 & Radiator thermostat & - $\quad$ Power Line Communication (PLC) \\
\hline
\end{tabular}

The list is not exhaustive since the network is supposed to be an open platform and, other sensors can be added as needed. Nevertheless, the higher the number of sensors and actuators, the more expensive is the solution. Since one of the aims of the project was to study a cheap, reliable and open domotics platform, particular attention was paid to realize a solution able to achieve good energy savings by means of few sensors accurately chosen. Table 2 also reports the communication modes among the sensors, with a preference for the wireless (in its general meaning) systems which are less intrusive and could be consequently easily mounted as a retrofit in existing buildings. The signals and information coming from each sensor/actuator are transmitted to an apartment gateway which implements simple diagnoses techniques (Table 3) and sends a feed-back to the final user (e.g. "warning" message). As an example, the undesired event of an external window open could be detected by a contact sensor mounted on each window; the same result can be obtained with the cheaper solution of monitoring the trend of internal temperature of the rooms: if the internal temperature decreases quickly compared to the usual temperature dynamic or if its value is nearer to the external temperature than to the set point. In the same way, a malfunctioning of thermostat or radiator thermostat can be detected by comparing the dynamic of internal ambient temperature with the setpoints set by the occupant. 
Table 3: Diagnosis connections between event and sensor.

\begin{tabular}{|c|c|c|}
\hline Event (Tab. 1) & Associated sensors/actuators (Table2) & Type of feed-back \\
\hline 1 & 1 AND/OR 2 & warning \\
\hline 2 & 1 AND 3 & warning \\
\hline 3 & 1 AND 3 AND 4 & warning \\
\hline
\end{tabular}

\section{Methodology: simulation of "occupant behaviours" and thermal profiles}

The purpose of the present work is twofold. On the one hand, it aims at evaluating, under an economic and energy point of view, the potential of reduction of primary energy achievable through energy conservation strategies supported by the interactive building architecture; on the other hand, it aims to attest methodologies for diagnosing inefficient occupant's behaviour and systems malfunctioning.

The goal was fulfilled by simulating a building on which different occupancy and thermal user's profiles were applied. At the beginning, for each combination of occupancy and thermal profile some energy conservation strategies were tested in order to be evaluated without behavioural or systems errors ("faultless profiles"). Successively, some "inefficient behaviours" or "systems malfunctioning" were added so that diagnosing methodologies could be tested.

\subsubsection{Building and occupancy "thermal" profile}

The considered building was a $100 \mathrm{~m}^{2}$ apartment with 4 rooms of different size. It was simulated by means of HAMBASE [11]. Two different heating consumption levels, of $105 \mathrm{kWh} / \mathrm{m}^{2} / \mathrm{y}$ (building A) and $75 \mathrm{kWh} / \mathrm{m}^{2} / \mathrm{y}$ (building B) respectively, were evaluated. The heating system consisted in a boiler fed by natural gas whose efficiency has been assumed equal to $90 \%$. The occupancy profiles were chosen among the most common programs preset in commercial thermostat and are shown in Table 4. Profile P1characterizes a dwelling occupied most of the day (by an old person, a housewife,...); P2 is the typical "worker" profile characterized by a heating thermal demand early in the morning and late in the afternoon and evening; profile P3 differs from P2 because of occupant presence during lunch time.

Table 4: $\quad$ Daily occupancy profiles.

\begin{tabular}{|l|c|c|c|c|c|c|c|c|c|c|c|c|c|c|c|c|c|c|c|c|c|c|c|c|}
\hline & 0 & 1 & 2 & 3 & 4 & 5 & 6 & 7 & 8 & 9 & 10 & 11 & 12 & 13 & 14 & 15 & 16 & 17 & 18 & 19 & 20 & 21 & 22 & 23 \\
\hline P1 & - & - & - & - & - & - & $\mathrm{x}$ & $\mathrm{x}$ & $\mathrm{x}$ & $\mathrm{x}$ & $\mathrm{x}$ & $\mathrm{x}$ & $\mathrm{x}$ & $\mathrm{x}$ & $\mathrm{x}$ & $\mathrm{x}$ & $\mathrm{x}$ & $\mathrm{x}$ & $\mathrm{x}$ & $\mathrm{x}$ & $\mathrm{x}$ & $\mathrm{x}$ & $\mathrm{x}$ & - \\
\hline P2 & - & - & - & - & - & - & $\mathrm{x}$ & $\mathrm{x}$ & $\mathrm{x}$ & - & - & - & - & - & - & - & - & $\mathrm{x}$ & $\mathrm{x}$ & $\mathrm{x}$ & $\mathrm{x}$ & $\mathrm{x}$ & $\mathrm{x}$ & - \\
\hline P3 & - & - & - & - & - & - & $\mathrm{x}$ & $\mathrm{x}$ & $\mathrm{x}$ & - & - & - & $\mathrm{x}$ & $\mathrm{x}$ & - & - & - & $\mathrm{x}$ & $\mathrm{x}$ & $\mathrm{x}$ & $\mathrm{x}$ & $\mathrm{x}$ & $\mathrm{x}$ & - \\
\hline
\end{tabular}




\subsubsection{Settings of thermal profiles}

According to the occupancy thermal profiles three conditions were simulated: i) absence of the thermostat in the house; ii) thermostat mounted only in one room; and iii) temperature controlled in each room by means of radiator thermostats. The absence of thermostat in the house was simulated considering an ON-OFF working mode of the boiler with an ambient temperature limited to $25^{\circ} \mathrm{C}$, temperature at which it is supposed that the user switched off the boiler. The thermostat installed just in one room was simulated with a temperature set both at $20^{\circ} \mathrm{C}$ and at $18^{\circ} \mathrm{C}$; in this case the simulation tool keeps the temperature at the set point only in the room where the thermostat is present whereas the temperature in the other rooms is a result of the simulation. Finally, the temperature controlled in each room was simulated by keeping two rooms at $20^{\circ} \mathrm{C}$ and two rooms at $18^{\circ} \mathrm{C}$; in this case was also tested a profile with two rooms kept at $18^{\circ} \mathrm{C}$ and the other two at $17^{\circ} \mathrm{C}$.

\section{Diagnosis techniques: multi-scale principal component analysis}

The Multi-Scale Principal Component Analysis (MSPCA) proposed by Bakshi [12] deals with processes that operate at different scales, and have contributions from: (i) events occurring at different localizations in time and frequency; (ii) stochastic processes whose energy or power spectrum changes with time and/or frequency; (iii) variables measured at different sampling rate or containing missing data.

MSPCA formulation captures events occurring at different scales by Principal Component Analysis (PCA) models. Moreover wavelets, with their timefrequency localization and multi-resolution properties, are used as a framework for multi-scale representation of data [13]. The primary motivation for jointly using PCA and Wavelet Transform comes from the idea that, in PCA, the correlation among sensors is used to transform the multivariate space into a subspace which preserves maximum variance of the original space. PCA does not utilize the information pertaining to the frequency or scale characteristics of the individual sensors. Wavelets, on the other hand, capture correlation within a sensor whereas PCA correlates across sensors [13]. The Multi Scale PCA (MSPCA) is a way to combine these two techniques, to extract maximum information from multivariate sensor data. For fault detection in the new sample, a deviation from the normal correlation could change the projections onto the PCA subspaces. The Square Prediction Error (SPE) is a statistic that measures lack of fit of a model to data. The SPE statistic indicates the difference, or residual, between a sample and its projection into the principal component subspace retained in the model. The exact description of the distribution of SPE is given in [14]. A confidence limit expression for SPE, when data follows a normal distribution, is developed in $[13,15]$. Once a defect is detected, the SPE contribution is computed and clustered to define a unique signature of the malfunction, that the diagnosis step is performed [16, 17]. In the IBN sector MSPCA take advantages from the fact that it does not need the building model 
since the diagnostic procedure is data driven and this is useful to adapt the algorithm to different buildings. Also, as confirmed by results, the MSPCA gives a response to the fault with a delay that depends on the scale depth that is only of few samples [16, 17].

The bad practices and malfunctioning listed in Table 1 were embedded in the building simulation code so that a set of ambient parameters was generated in order to test the MSPCA diagnosis technique. Figure 1 shows an example of the trend of the temperature monitored in one room of the building kept by a smart thermostat at $18^{\circ} \mathrm{C}$ during two days (Profile 1). During the second day a window is opened for 2 hours.

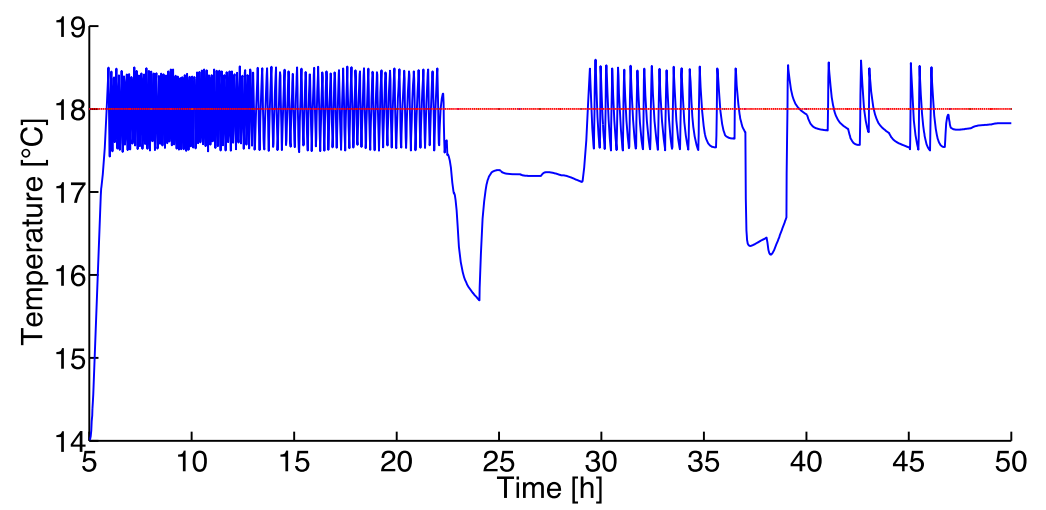

Figure 1: $\quad$ Example of a room kept at $18^{\circ} \mathrm{C}$.

Figure 2 shows the trend of the SPE index in the event of a bad practice (external window open) occurring: the index rises over the threshold as the bad practice is detected and return below it once a correction action is performed.

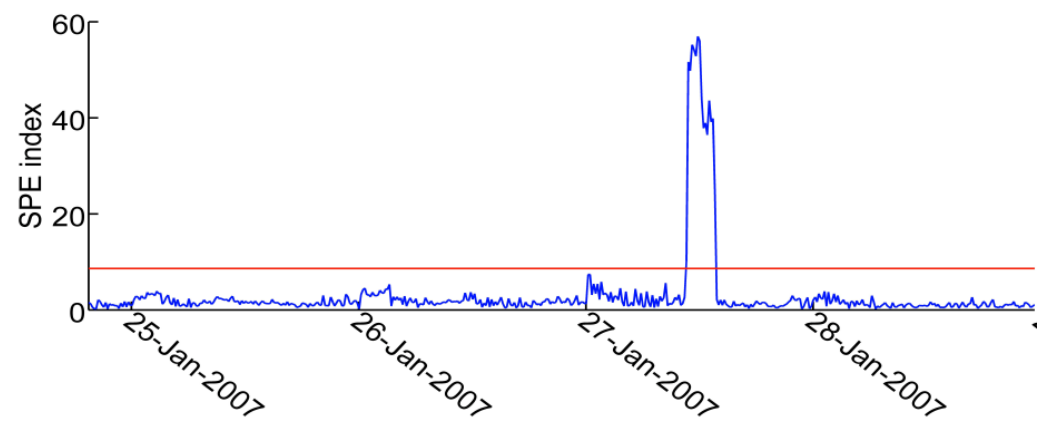

Figure 2: Trend of SPE index in the case of undesired event occurring.

Table 5 shows the identification stage performed by SPE contribution analysis, the SPE index value is given by a set of sensor depending on the type of malfunction or bad practice happened. 
Table 5: $\quad$ SPE Contribution of sensors.

\begin{tabular}{|c|c|c|}
\hline$\#$ & Event to diagnose & SPE Contribution of Sensors \\
\hline 1 & Openings of external doors and windows & Room temperature over threshold \\
\hline 2 & Malfunctioning of thermostat & $\begin{array}{c}\text { Room temperature over threshold } \\
\text { Room humidity over threshold }\end{array}$ \\
\hline 3 & Malfunctioning of radiator thermostat & $\begin{array}{c}\text { Radiator valve position over } \\
\text { threshold }\end{array}$ \\
\hline
\end{tabular}

\section{Results analysis and discussion}

Since the goal of the work is evaluating the environmental and economic gain achievable by the interactive building network, the results are presented mainly as energy consumptions ( $\mathrm{kWh}$ of thermal energy and $\mathrm{m}^{3}$ of natural gas) and natural gas charges (not including fixed costs but only variable cost due to natural gas consumption). Tables 6 and 7 show that independently of the user profile the best practices have a fundamental role in curbing energy consumptions for thermal heating. Nevertheless, it is worth noting that the higher the initial energy performance the lower the marginal energy and economic benefits. This can be seen both by comparing the results of the two buildings with different energy performances and, being equal the building and the profile, by comparing the different energy conservation strategies. Table 6 and 7 show also that the ambient temperature set is the main parameter affecting energy consumptions.

Table 6: $\quad$ Energy and economic results for building A.

\begin{tabular}{|c|c|c|c|c|c|c|}
\hline & & $\begin{array}{l}\text { Without } \\
\text { thermostat }\end{array}$ & $\begin{array}{c}1 \\
\text { thermostat } \\
\text { set at } 20^{\circ} \mathrm{C} \\
\end{array}$ & $\begin{array}{l}4 \text { thermostats } \\
\text { set at } 18, \\
20,18,20^{\circ} \mathrm{C}\end{array}$ & $\begin{array}{c}1 \\
\text { thermostat } \\
\text { set at } 18^{\circ} \mathrm{C}\end{array}$ & $\begin{array}{c}4 \text { thermostats } \\
\text { set at } 17,18 \text {, } \\
17,18^{\circ} \mathrm{C}\end{array}$ \\
\hline \multirow{3}{*}{$\begin{array}{l}\overline{0} \\
\frac{0}{0} \\
0\end{array}$} & $\begin{array}{c}\text { Yearly primary energy } \\
\text { consumption }[\mathrm{kWh}]\end{array}$ & 10699 & 8957 & 7819 & 6225 & 6124 \\
\hline & $\begin{array}{l}\text { Yearly natural gas } \\
\text { consumption }\left[\mathrm{m}^{3}\right]\end{array}$ & 1126 & 943 & 823 & 655 & 645 \\
\hline & $\begin{array}{c}\text { Yearly natural gas } \\
\text { variable charges }[€]\end{array}$ & 597 & 500 & 436 & 347 & 342 \\
\hline \multirow{3}{*}{ 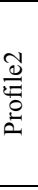 } & $\begin{array}{c}\text { Yearly primary energy } \\
\text { consumption [kWh] }\end{array}$ & 9682 & 7645 & 6833 & 5506 & 5271 \\
\hline & $\begin{array}{l}\text { Yearly natural gas } \\
\text { consumption }\left[\mathrm{m}^{3}\right]\end{array}$ & 1019 & 805 & 719 & 580 & 455 \\
\hline & $\begin{array}{c}\text { Yearly natural gas } \\
\text { variable charges }[€]\end{array}$ & 540 & 426 & 381 & 307 & 294 \\
\hline \multirow{3}{*}{ 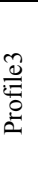 } & $\begin{array}{l}\text { Yearly primary energy } \\
\text { consumption [kWh] }\end{array}$ & 10250 & 8138 & 7320 & 5850 & 5632 \\
\hline & $\begin{array}{l}\text { Yearly natural gas } \\
\text { consumption }\left[\mathrm{m}^{3}\right]\end{array}$ & 1079 & 857 & 771 & 616 & 593 \\
\hline & $\begin{array}{c}\text { Yearly natural gas } \\
\text { variable charges }[€]\end{array}$ & 572 & 454 & 408 & 326 & 314 \\
\hline
\end{tabular}


Table 7: $\quad$ Energy and economic results for building B.

\begin{tabular}{|c|c|c|c|c|c|c|}
\hline & & $\begin{array}{l}\text { Without } \\
\text { thermostat }\end{array}$ & $\begin{array}{c}1 \\
\text { thermostat } \\
\text { set at } 20^{\circ} \mathrm{C}\end{array}$ & $\begin{array}{c}4 \text { thermostats } \\
\text { set at } 18,20 \text {, } \\
18,20^{\circ} \mathrm{C}\end{array}$ & $\begin{array}{c}1 \\
\text { thermostat set } \\
\text { at } 18^{\circ} \mathrm{C}\end{array}$ & $\begin{array}{c}4 \text { thermostats } \\
\text { set at } 17,18 \text {, } \\
17,18^{\circ} \mathrm{C}\end{array}$ \\
\hline \multirow{3}{*}{$\begin{array}{l}\overrightarrow{0} \\
\frac{0}{0} \\
0\end{array}$} & $\begin{array}{l}\text { Yearly primary energy } \\
\text { consumption }[\mathrm{kWh}]\end{array}$ & 7925 & 6635 & 5792 & 4611 & 4537 \\
\hline & $\begin{array}{l}\text { Yearly natural gas } \\
\text { consumption }\left[\mathrm{m}^{3}\right]\end{array}$ & 834 & 698 & 610 & 485 & 478 \\
\hline & $\begin{array}{c}\text { Yearly natural gas } \\
\text { variable charges }[€]\end{array}$ & 442 & 370 & 323 & 257 & 253 \\
\hline \multirow{3}{*}{ 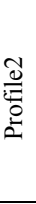 } & $\begin{array}{l}\text { Yearly primary energy } \\
\text { consumption }[\mathrm{kWh}]\end{array}$ & 7172 & 5663 & 5062 & 4079 & 3905 \\
\hline & $\begin{array}{l}\text { Yearly natural gas } \\
\text { consumption }\left[\mathrm{m}^{3}\right]\end{array}$ & 755 & 596 & 533 & 429 & 411 \\
\hline & $\begin{array}{c}\text { Yearly natural gas } \\
\text { variable charges }[€]\end{array}$ & 400 & 316 & 282 & 228 & 218 \\
\hline \multirow{3}{*}{ 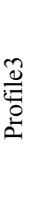 } & $\begin{array}{l}\text { Yearly primary energy } \\
\text { consumption }[\mathrm{kWh}]\end{array}$ & 7593 & 6028 & 5422 & 4333 & 4172 \\
\hline & $\begin{array}{l}\text { Yearly natural gas } \\
\text { consumption }\left[\mathrm{m}^{3}\right]\end{array}$ & 799 & 635 & 571 & 456 & 439 \\
\hline & $\begin{array}{c}\text { Yearly natural gas } \\
\text { variable charges }[€]\end{array}$ & 424 & 336 & 303 & 242 & 233 \\
\hline
\end{tabular}

Table 8 and 9 show the emissions of $\mathrm{CO}_{2}$ and $\mathrm{NO}_{\mathrm{X}}$ associated with each combination of building performance, user profile and energy conservation strategies [9]. Table 8 and 9 do not present the emissions of VOC because the calculation assumes the perfect combustion of the natural gas. As previously explained, one of the aims of the work was the evaluation of diagnosis techniques on the basis of the data (e.g. internal temperature profiles) generated by the simulation. In the previous paragraph we demonstrated the effectiveness of these techniques. However, the energy and economic evaluation of "fault" profiles is difficult to carry out as it is affected by the boundary conditions forced by the modeller in the simulations. For this reason, the main output is not a single value of energy or monetary saving but its order of magnitude. As an example: the simulation of the profile 1 , with one thermostat set at $20^{\circ} \mathrm{C}$, for the building with an heating consumption of $75 \mathrm{kWh} / \mathrm{m}^{2} / \mathrm{y}$ gives as a result a natural gas consumption of $698 \mathrm{~m}^{3} / \mathrm{y}$; assuming that the occupant leaves an external window open once a week for 2 hours between 13.00 and 15.00 the natural gas new consumption would be of $714 \mathrm{~m}^{3} / \mathrm{y}$, with an increment of about $16 \mathrm{~m}^{3} / \mathrm{y}$ corresponding to: i) an increase of about $2 \%$ of the primary energy consumption; ii) an extra yearly charge of about $10 €$; iii) higher emissions of $28 \mathrm{~kg} \mathrm{of} \mathrm{CO}_{2}$ and $22 \mathrm{~kg}$ of $\mathrm{NO}_{\mathrm{X}}$. The results would have been different if, for instance: i) the early morning or the late evening hours of the day were chosen, instead of the warmer ones; or ii) another time duration was chosen (1 or 3 hours instead of 2). The interactive building network architecture proposed has the aim of increasing the energy awareness of household final users. The results presented lead to some technical and economic considerations. First, the main key of result interpretation is the "marginal" energy and economic benefit. In fact, the adoption of energy conservation strategies or diagnostic solutions is the result of 
Table 8: $\quad$ Emissions of building A.

\begin{tabular}{|c|c|c|c|c|c|c|}
\hline & & $\begin{array}{c}\text { Without } \\
\text { thermostat }\end{array}$ & $\begin{array}{c}1 \text { thermostat } \\
\text { set at } 20^{\circ} \mathrm{C}\end{array}$ & $\begin{array}{c}4 \text { thermostats set } \\
\text { at } 18,20,18,20^{\circ} \mathrm{C}\end{array}$ & $\begin{array}{c}1 \text { thermostat } \\
\text { set at } 18^{\circ} \mathrm{C}\end{array}$ & $\begin{array}{c}4 \text { thermostats set } \\
\text { at } 17,18,17,18^{\circ} \mathrm{C}\end{array}$ \\
\hline \multirow{2}{*}{$\mathrm{P} 1$} & $\mathrm{CO}_{2}(\mathrm{~kg})$ & 1949 & 1632 & 1424 & 1133 & 1116 \\
\cline { 2 - 7 } & $\mathrm{NO}_{\mathrm{X}}(\mathrm{kg})$ & 1540 & 1290 & 1126 & 896 & 882 \\
\hline \multirow{2}{*}{$\mathrm{P} 2$} & $\mathrm{CO}_{2}(\mathrm{~kg})$ & 1763 & 1393 & 1244 & 1004 & 787 \\
\cline { 2 - 7 } & $\mathrm{NO}_{\mathrm{X}}(\mathrm{kg})$ & 1394 & 1101 & 984 & 793 & 622 \\
\hline \multirow{2}{*}{$\mathrm{P} 3$} & $\mathrm{CO}_{2}(\mathrm{~kg})$ & 1867 & 1483 & 1334 & 1066 & 1026 \\
\cline { 2 - 7 } & $\mathrm{NO}_{\mathrm{X}}(\mathrm{kg})$ & 1476 & 1172 & 1055 & 843 & 811 \\
\hline
\end{tabular}

Table 9: $\quad$ Emissions of building B.

\begin{tabular}{|c|c|c|c|c|c|c|}
\hline & & $\begin{array}{c}\text { Without } \\
\text { thermostat }\end{array}$ & $\begin{array}{c}1 \text { thermostat } \\
\text { set at } 20^{\circ} \mathrm{C}\end{array}$ & $\begin{array}{c}4 \text { thermostats set at } \\
18,20,18,20^{\circ} \mathrm{C}\end{array}$ & $\begin{array}{c}1 \text { thermostat } \\
\text { set at } 18^{\circ} \mathrm{C}\end{array}$ & $\begin{array}{c}4 \text { thermostats set at } \\
17,18,17,18^{\circ} \mathrm{C}\end{array}$ \\
\hline \multirow{2}{*}{$\mathrm{P} 1$} & $\mathrm{CO}_{2}(\mathrm{~kg})$ & 1443 & 1208 & 1056 & 839 & 827 \\
\cline { 2 - 7 } & $\mathrm{NO}_{\mathrm{X}}(\mathrm{kg})$ & 1141 & 955 & 834 & 663 & 654 \\
\hline \multirow{2}{*}{$\mathrm{P} 2$} & $\mathrm{CO}_{2}(\mathrm{~kg})$ & 1307 & 1031 & 922 & 742 & 711 \\
\cline { 2 - 7 } & $\mathrm{NO}_{\mathrm{X}}(\mathrm{kg})$ & 1033 & 815 & 729 & 587 & 562 \\
\hline \multirow{2}{*}{$\mathrm{P} 3$} & $\mathrm{CO}_{2}(\mathrm{~kg})$ & 1383 & 1099 & 988 & 789 & 760 \\
\cline { 2 - 7 } & $\mathrm{NO}_{\mathrm{X}}(\mathrm{kg})$ & 1093 & 869 & 781 & 624 & 601 \\
\hline
\end{tabular}

the trade-off between initial cost and economic saving achievable. In this sense, the installation of a thermostat has one of the best ratio between investment and saving; in fact, the annual economic saving ranges between 70 and $100 €$ (ambient temperature set at $20^{\circ} \mathrm{C}$ ) when its cost is about $120 €$. The installation of radiator thermostats in each of the 4 rooms, although efficient, entails a higher cost, in the range of 400-500 $€$ but the annual saving ranges from 30 to $70 €$, so that their adoption should be carefully evaluated since the PBP could be long; furthermore, similar results could be achieved by setting a lower temperature in the thermostat. A second remark regards the economic saving achievable with the diagnostics of bad behaviours. Referring to the example reported in the previous section related to the opening of an external window two hours per week, the saving of $16 \mathrm{~m}^{3}$ of natural gas, corresponding to a higher annual cost of about $10 €$, could be considered not worthy of attention. However, if the apartment has a security system provided with contact sensors mounted on the external windows, the energy diagnosis could be easily enacted cost free; the installation of temperature sensors, assuming a payback period of 3-5 years, should not exceed a cost of 50-60 €. This second remark is one of the key points of this work. In fact, energy diagnosis of bad behaviours could sometimes result in low or even negligible savings for the final users who are not urged into energy saving. Nevertheless, the household sector is one of the biggest aggregate consumers in most countries and this is the reason why, in recent years, increasingly policies have been considering it: the sum of a high number of small 
energy saving actions could represent a large energy saving if considered as a whole. By way of example, under this point of view, conservatively extending the $16 \mathrm{~m}^{3}$ saved in the previous example to half of 32,733 heating system (whose thermal power size is lower than $35 \mathrm{kWt}$ ) of the city of Pesaro, leads to an annual saving of $261,864 \mathrm{~m}^{3}$ of natural gas, and to annual avoided emissions of $\mathrm{CO}_{2}$ and $\mathrm{NO}_{\mathrm{X}}$ equal to 453 tons and 358 tons, respectively. The third remark deals with the cost of the interactive building network architecture proposed. In fact, the maximum yearly economic savings achievable are: $\sim 250 €$ and $\sim 190 €$ for the buildings whose heating consumption is 105 and $75 \mathrm{kWh} / \mathrm{m}^{2} / \mathrm{y}$, respectively. In order to be widely adopted, systems such as the one proposed must pay back in a reasonable period for the final user. Considering a PBP of 3-5 years, a rough estimate of the architecture cost should range between 600 and $1500 €$, according to different solutions. Finally, it is important to stress an implicit limit of the analysis proposed for the IBN which is the "occupant response" to the "warning" feed-back. In fact, one needs to take into account subjective and behavioural factors which may lead to widely different results for similar situations; some examples: does the warning refer to an occasional event or to a frequent or recurrent one? After the occupant received the feed-back how long does it take for the occupant to correct it? Or even: does the occupant actually take any action after the feed back?

\section{Conclusions}

The work presented the architecture of an Interactive Building Network whose aim is to (i) suggest energy conservation strategies to the final user and (ii) diagnose inefficient occupant behaviours or system malfunctioning. In particular, the architecture focuses on monitoring thermal heating energy due to its higher impact in the household sector consumption compared to electrical energy. The architecture mainly consists in few sensors remotely communicating with an apartment gateway so that the system could be easily retrofitted to existing buildings. The marginal energy and economic benefits achievable were evaluated. Even if sometimes they could be considered not worthy of attention by the final user due to their relatively small amount, the aggregate savings achievable in the household sector could highly reduce the consumption of natural gas, a major responsible of urban air pollution, contributing to lower $\mathrm{NO}_{\mathrm{X}}$ and $\mathrm{VOC}$ other than reduce $\mathrm{CO}_{2}$ emissions. In order to be widely adopted domotics systems such as the one proposed should have an initial cost considered reasonable by final users; assuming a PBP of 3-5 years, the initial cost should range between 600 and $1500 €$, depending on the final user energy conditions.

\section{Acknowledgements}

The authors wish to thank Mauro Annunziato of ENEA and Professors Fabio Polonara and Sauro Longhi of Università Politecnica delle Marche.

The work was carried out within the Agreement between "Ministero dello Sviluppo Economico" and ENEA on Research in the Electric System. 


\section{References}

[1] Quinto Rapporto Annuale sul meccanismo dei titoli di efficienza energetica Situazione al 31 maggio 2010, 23 marzo 2011.

[2] Confindustria. Confederation of Italian Industry. Proposte per il Piano Nazionale di efficienza energetica (Proposals for the energy efficiency National plan), in Italian, 2006 http://www.confindustria.it/

[3] ISPRA, Institute for Environmental Protection and Research http://annuario.apat.it/capitoli/Ver_7/tem/03\%20Aria.pdf

[4] Faiers, A., Cook, M. \& Neame, C., Towards a contemporary approach for understanding consumer behaviour in the context of domestic energy use. Energy Policy 35 pp. 4381-4390, 2007.

[5] Lindén, A., Carlsson-Kanyamab, A., \& Eriksson, B., Efficient and inefficient aspects of residential energy behaviour: What are the policy instruments for change? Energy Policy 34, pp. 1918-1927, 2006.

[6] Pesaro Municipality, http://www.pesaroenergia.it/index.php?id=10057

[7] DOE, U.S. Department of Energy, Office of Energy Efficiency and Renewable Energy (EERE) http:/www1.eere.energy.gov/buildings/ appliance_standards/residential/pdfs/furnaces_boilers/fb_tsd_appendixw_0 906.pdf

[8] IPCC. Guidelines for national greenhouse gas inventories; 2006.

[9] UNI EN 483, 2004.

[10] Tremblay, K. R., Energy Conservation in the Home no. 10.610. Consumer Series. Colorado State University, http://www.ext.colostate.edu/pubs/ consumer/10610.pdf

[11] De Wit, M., HAMBASE Heat air and moisture model for building and system evolution. Bouwstenen series of the department of Architecture, Building and Planning of the Eindhoven University of Technology, Eindhoven University Press, 2006. http://sts.bwk.tue.nl/hamlab/readers /bouwsteen 100.pdf

[12] Bakshi, B. R., Multiscalepca with application to multivariate statistical process monitoring, AIChE Journal 44, pp. 1596-1610, 1998.

[13] Manish, M., Yuea, H. H., Qin, S. J. \& Ling, C., Multivariate process monitoring and fault diagnosis by multi-scale pca, Computers \& Chemical Engineering 26, pp. 1281-1293, 2002.

[14] Jackson, J. E., A User's Guide to Principal Components, WileyInterscience, New York, 2003.

[15] Jackson, J. \& Mudholkar, G., Control procedures for residuals associated with principal component analysis, Technometrics 21 pp. 341-349, 1979.

[16] Ferracuti, F., Giantomassi, A., Ippoliti, G. \& Longhi, S., Multi-Scale PCA based fault diagnosis for rotating electrical machines. Proceedings of the 8th ACD 2010 European Workshop on Advanced Control and Diagnosis, pp. 296-301, 2010.

[17] Ferracuti, F., Giantomassi, A., Longhi, S. \& Bergantino, N., Multi-Scale PCA based fault diagnosis on a paper mill plant. 16th IEEE International Conference on Emerging Technologies and Factory Automation, ETFA 2011. 